\title{
Cross-Cultural Adaptation and Analysis of the Psychometric Properties of the Portuguese Version of the Edinburgh Feeding Evaluation in Dementia Scale
}

\author{
Lígia Passos $^{a, b, c}$ João Tavares ${ }^{c, d}$ Daniela Figueiredoc, d \\ ${ }^{a}$ Department of Education and Psychology, University of Aveiro, Aveiro, Portugal; ${ }^{b}$ Institute of Biomedical Sciences \\ Abel Salazar, University of Porto, Porto, Portugal; 'Center for Health Technology and Services Research, Aveiro, \\ Portugal; ${ }^{d}$ School of Health Sciences, University of Aveiro, Aveiro, Portugal
}

\author{
Keywords \\ Dementia · Feeding difficulties · Assessment tool · Internal \\ consistency · Reliability
}

\begin{abstract}
Introduction: In advanced stages, people with dementia (PwD) may develop feeding difficulties. The assessment of these difficulties is the first step towards an adequate intervention. The Edinburgh Feeding Evaluation in Dementia Scale (EdFED) is an instrument for assessing the feeding difficulties of older PwD. Objective: The objective of this observational, cross-sectional, exploratory-descriptive study was to contribute to the adaptation of the EdFED to the Portuguese population and to analyze some of its psychometric properties, namely internal consistency and interobserver reliability. Methods: First, translation, cultural and linguistic adaptation, as well as validation were performed using an expert panel and calculation of the content validity index (CVI). Then the instrument was applied in 51 institutionalized older PwD (mean age $86.06 \pm 6.77$ years, $86.2 \%$ women). Results: The results showed excellent content validity, with a CVI of 0.950. The Portuguese version of the EdFED showed reasonable internal consistency (Cronbach's $a=0.705)$ and
\end{abstract}

very satisfactory interobserver reliability (Cohen's $\mathrm{K}=0.882$ ). Conclusion: The main results suggest that the Portuguese version of the EdFED is a reliable instrument that allows the assessment of eating/feeding difficulties among institutionalized older PwD.

(c) 2021 The Author(s). Published by S. Karger AG, Basel on behalf of NOVA National School of Public Health

\section{Adaptação transcultural e análise das propriedades psicométricas da versão portuguesa da Edinburgh Feeding Evaluation in Dementia Scale}

\section{Palavras Chave}

Demência · Dificuldades de alimentação · Instrumento de avaliação · Consistência interna · Fiabilidade

\section{Resumo}

Introdução: Em estádios avançados, pessoas com demência podem desenvolver dificuldades de alimentação. A avaliação dessas dificuldades é o primeiro passo para uma intervenção adequada. A Edinburgh Feeding Evaluation in Dementia Scale (EdFED) é um instrumento de avaliação karger@karger.com www.karger.com/pjp

Karger $\stackrel{\text { ' }}{5}$

GOPEN ACCESS (c) 2021 The Author(s). Published by S. Karger AG, Basel on behalf of NOVA National School of Public Health

This is an Open Access article licensed under the Creative Commons Attribution-NonCommercial-4.0 International License (CC BY-NC) (http://www.karger.com/Services/OpenAccessLicense), applicable to the online version of the article only. Usage and distribution for commercial purposes requires written permission.
Lígia Passos

Department of Education and Psychology, University of Aveiro Campus Universitário de Santiago, Edifício 5

PT-3810-193 Aveiro (Portugal)

ligiamaria@ua.pt 
das dificuldades alimentares de idosos com demência. Objetivo: O objetivo deste estudo observacional, transversal, exploratório-descritivo foi contribuir para a adaptação da EdFED para a população portuguesa e analisar algumas das suas propriedades psicométricas, nomeadamente consistência interna e fiabilidade inter-observador. Métodos: Primeiramente, foi realizada a tradução, adaptação cultural e linguística e validação, por meio de painel de especialistas e cálculo do índice de validade de conteúdo. Em seguida, o instrumento foi aplicado em 51 idosos institucionalizados com demência (idade média = $86,06 \pm 6,77,86,2 \%$ mulheres). Resultados: Os resultados mostraram excelente validade de conteúdo, com IVC de 0,950 . A versão portuguesa da EdFED apresentou razoável consistência interna (a de Cronbach $=0,705$ ) e fiabilidade inter-observador muito satisfatória ( $\mathrm{\kappa}$ de Cohen = 0,882). Conclusão: Os principais resultados sugerem que a versão portuguesa da EdFED é um instrumento fiável que permite avaliar as dificuldades alimentares de idosos institucionalizados com demência.

(c) 2021 The Author(s). Published by S. Karger AG, Basel on behalf of NOVA National School of Public Health

\section{Introduction}

About 50 million people worldwide lived with dementia in 2018, with a new case being diagnosed every $3 \mathrm{sec}-$ onds. Projections estimate that in 2030 that number will have increased to 82 million people, reaching 152 million people in 2050 [1]. In Portugal, it is estimated that 182,000 people live with dementia [2], with about 19.9 cases per 1,000 inhabitants, being the country with the fourth highest number of cases in the world [3]. In advanced stages, people with dementia $(\mathrm{PwD})$ may experience feeding difficulties, usually manifested by oropharyngeal dysphagia, refusal to eat, and aversive behaviors, among others $[4,5]$.

The Edinburgh Feeding Evaluation in Dementia Scale (EdFED) [6] is a widely validated scale that measures feeding difficulties in PwD based on their eating behaviors [7-11]. The EdFED can detect feeding difficulties even in people with severe cognitive impairment, when the usual instruments are less effective in detecting functional decline [12]. It is a 10-item questionnaire, easy and quick to apply, which assesses and monitors changes in PwD eating behavior. The first two items refer to the need for assistance during meals. Items 3 and 4 are indicators of the person's difficulty in feeding herself/himself. Items 5-10 describe feeding behaviors, ranging from refusing food to keeping the mouth open while eating [10]. Each

Portuguese Adaptation of the Edinburgh

Feeding Evaluation in Dementia Scale item is scored according to the frequency of its occurrence during the meal: 0 if the behavior never happens, 1 if it happens sometimes, and 2 if it happens often. The final score ranges from 0 to 20 . A higher score indicates higher impairment [12].

Studies of psychometric properties showed that the EdFED has a high internal consistency (Cronbach's $\alpha=$ 0.87 ), validity of construct, as well as inter- and intrarater reliability $(r=59, p=0.013$ and $r=0.95, p<0.000$, respectively) [13].

The instrument has the same precision when measuring behaviors through direct observation or the caregiver's report [12]. It is recommended by the European Society for Clinical Nutrition and Metabolism to identify eating problems and behavioral symptoms in $\mathrm{PwD}$ [14] and is also considered by the Hartford Institute of Geriatric Nursing, New York University as the best tool to assess feeding difficulties in older PwD [15]. Currently, there are validated versions for traditional and simplified Chinese [7, 8], Spanish [9], French [10], and Italian [11]. However, there is no European Portuguese version of the EdFED.

The main objective of this study was to translate and adapt the EdFED into the Portuguese language. Second, the study aimed to evaluate its psychometric properties (internal consistency and interobserver reliability) in a sample of Portuguese institutionalized PwD. Finally, a brief characterization of the feeding difficulties presented by the studied sample was carried out.

\section{Subjects and Methods}

\section{Design and Participants}

An observational, transversal, exploratory-descriptive study was conducted with a convenience sample of institutionalized PwD between July and December 2019. First, the EdFED was translated, culturally adapted, and linguistically validated. Then, a study of its psychometric properties was developed, namely internal consistency and interobserver reliability. Participants were selected from nursing homes in the central region of Portugal. The inclusion criteria were (1) $\geq 65$ years old, (2) diagnosis of dementia recorded in the clinical file, (3) institutionalization for at least 2 months, (4) feeding difficulty requiring supervision and/or direct help during meals identified and reported by the nursing home director and/or nurses in charge, and (5) presence of a legal proxy to sign the consent form. Those who fed independently as well as those who were fed exclusively by nasogastric tube or gastrostomy were excluded.

\section{Translation and Adaptation Procedures}

Permission for the development of the European Portuguese version of the EdFED was obtain from its author, Dr. Roger Watson. The linguistic validation process followed the princi- 
ples of good practice for translation and cultural adaptation proposed by the International Society for Pharmacoeconomics and Outcomes Research [16]. First, a translation into the Portuguese language was done by the first author of this study, who has good skills of the English language and professional knowledge in health, aging, dementia, and feeding. Then, a reconciliation was made by the co-authors of this study. After review, adaptation of the initial translation, and discussion for consensus, the first version of the EdFED-PT was obtained. A retroversion into English was performed by a faculty professor whose mother language is English but who has advanced knowledge of European Portuguese. For harmonization, all translators compared versions, with item-by-item analysis, resulting in version 2 of the EdFED-PT. In the cognitive debriefing stage, whose main objective was to check the understandability, interpretation, and cultural relevance of the translation [16], an expert panel with health professionals and/or faculty teachers/researchers was formed to analyze the translation of the EdFED. The group analyzed each item in order to verify their understanding and meaning, thus reducing the ambiguity of understanding. With the conclusion of this analysis, version 3 of the EdFED-PT was created. Finally, an orthographic revision of version 3 was done by a Portuguese language teacher for possible corrections, giving rise to the final version of the EdFED-PT.

For the cognitive debriefing, eight health professionals and/or faculty teachers/researchers were invited in a nonprobabilistic convenience sample. The choice was made due to the knowledge on the subject of the study, academic degree, and experience in the referred area and respective target population. Regarding profession, the sample consisted of one social worker, one nurse, three gerontologists, one psychologist, and two speech therapists.

Each expert was instructed to assess the degree of agreement between the original version and the translation synthesis, observing the aspects of semantic, idiomatic, and experiential or cultural equivalence, and had to indicate the degree of agreement between the original version and the synthesis of the translation of each item of the EdFED on a scale from 1 to 4 , which corresponds to 1 $=$ disagree, 2 = slightly agree, $3=$ agree, and $4=$ totally agree. When grades 1 or 2 were marked, experts were asked to justify their choice and to write down observations and suggestions in a specific field. An agreement of $80 \%$ was stipulated to determine consensus among the experts, and the items with lower agreement were re-evaluated in a second round, considering the information of what was not consensual in the group's opinion, and they were able to maintain or modify their opinion.

For the analysis of content validity, the criteria proposed by Polit and Beck [17] were followed, through the content validity index (CVI), which measures the degree of satisfaction of the panel of experts when evaluating an instrument, and it is calculated by adding the items measured as 3 or 4 to be divided by the total number of responses. The probability of change and modified $\kappa$ was also calculated, which is a consensus index of the agreement between the evaluators that complements the CVI, removing the random chance agreement [18].

Assessment of the Psychometric Properties of the EdFED-PT

This phase of the study was performed in six nursing homes in central Portugal and consisted of the application of the EdFED-PT. The behavior of $51 \mathrm{PwD}$ was observed during lunch. The meals of 40 participants (mean age $85.77 \pm 7.15$ years, $87.5 \%$ female) were observed simultaneously by the main researcher and a psychologist with academic formation in gerontology and geriatrics and well-versed in the use of the instrument, in order to analyze the interobserver reliability.

\section{Statistical Analysis}

For sample characterization, descriptive statistics were used through the calculation of absolute frequencies and measures of central tendency and dispersion (mean and standard deviation). Internal consistency was assessed by Cronbach's $\alpha$, and it is considered very good at $>0.9$, good at $0.8-0.9$, reasonable at $0.7-0.8$, weak at $0.6-0.7$, and inadmissible at $<0.6$ [19]. The interobserver reliability assessment was carried out by Cohen's $\kappa$, whose values vary between 0 and 1 , and although there is some variation in the interpretation of its values, the proposal by Landis and Koch [20] is one of the best-accepted: $<0=$ poor, $0.00-0.20=$ weak, $0.21-$ 0.40 = considerable, $0.41-0.60=$ moderate, $0.61-0.80=$ substantial, and $0.81-1.00=$ almost perfect. The percentage of agreement between the observers was also calculated.

In inferential statistics, for the study of the relationship between sociodemographic variables and the total EdFED score, nonparametric tests were chosen: Mann-Whitney U test for comparison of two independent categories and Spearman's coefficient to verify the degree of relationship between two variables. Inferential results $<0.05$ were considered significant. Analysis of the results was performed with the support of the SPSS statistics software (IBM Corp., Armonk, NY, USA) version 25.

\section{Results}

\section{Content Validity}

At the end of the first evaluation round, three items from the EdFED-PT had a CVI <0.8. After the second round, two items had a CVI of 1 and the other had a CVI of 0.875 . The mean value of the CVI at the end of the evaluations was 0.950 . The probability of change values varied between 0.004 and 0.0313 . The modified $\kappa$ varied between 0.52 and 1 , with a mean $\kappa$ value of 0.94 , being considered excellent (Table 1). After the two rounds no expert suggested any changes in the translations that pointed to the need of cultural adaptations.

\section{Participants}

A total of 51 institutionalized $\mathrm{PwD}$ participated in this study. The mean age was $86.06 \pm 6.77$ years and the majority were women $(n=44,86.2 \%)$. Most participants were widowed $(n=36,70.5 \%)$ and had a low academic qualification (Table 2).

\section{Internal Consistency}

To verify the internal consistency of the EdFED-PT, Cronbach's a was calculated, obtaining a total score of 0.705 . Items 6 and 8 show the lowest item-total correla- 
Table 1. Analysis of EdFED-PT content validity

\begin{tabular}{|c|c|c|c|c|c|c|c|c|}
\hline 2 & 0.75 & 1 & 0.12 & 0.004 & 0.72 & 1 & good & excellent \\
\hline 3 & 0.875 & - & 0.0313 & - & 0.87 & - & excellent & excellent \\
\hline 4 & 1 & - & 0.004 & - & 1 & - & excellent & excellent \\
\hline 7 & 1 & - & 0.004 & - & 1 & - & excellent & excellent \\
\hline 8 & 0.875 & - & 0.0313 & - & 0.87 & - & excellent & excellent \\
\hline 9 & 0.75 & 0.875 & 0.12 & 0.0313 & 0.72 & 0.87 & good & excellent \\
\hline 10 & 1 & - & 0.004 & - & 1 & - & excellent & excellent \\
\hline
\end{tabular}

PC was calculated using the formula $[\mathrm{N}$ ! / $\mathrm{A}$ ! $(\mathrm{N}-\mathrm{A})$ !] where $\mathrm{N}=$ the number of experts and $\mathrm{A}=$ the number of experts who agree that the item is relevant. Kappa was calculated using the formula $\kappa=$ CVI - PC / (1 - PC). Interpretation criteria for $\kappa[17,18]$ : fair $=\kappa$ from 0.40 to 0.59 ; good $=\kappa$ from 0.60 to 0.74 ; excellent $=\kappa>0.74$. CVI, content validity index; EdFED-PT, Portuguese version of the Edinburgh Feeding Evaluation in Dementia Scale; PC, probability of change.

Table 2. Sociodemographic data $(n=51)$

\begin{tabular}{lc}
\hline Variable & \\
\hline Age, years & $86.06 \pm 6.77$ \\
Institutionalization time, years & $6.6 \pm 6.43$ \\
Sex & \\
$\quad$ Female & $44(86.2 \%)$ \\
Male & $7(13.8 \%)$ \\
Education & \\
No qualification & $8(15.7 \%)$ \\
Primary school & $25(49.0 \%)$ \\
Secondary school & $1(2.0 \%)$ \\
High school/university & $5(9.8 \%)$ \\
No registration & $12(23.5 \%)$ \\
Marital status & \\
Single & $8(15.7 \%)$ \\
Married & $6(11.7 \%)$ \\
Divorced & $1(2.1 \%)$ \\
Widowed & $36(70.5 \%)$ \\
\hline
\end{tabular}

Values are presented as mean \pm standard deviation or $n(\%)$.

tion scores (0.229) and item 10 the highest one (0.663) (Table 3).

\section{Interobserver Reliability}

For the study of EdFED-PT interobserver reliability, a sample of $40 \mathrm{PwD}$ was considered. The value of the total Cohen's $\kappa$ obtained was 0.882 and the percentage of agreement between the observers was $98.5 \%$ (Table 4 ).

\section{Study of Feeding Difficulties}

The mean total score among the 51 participants was $5.45 \pm 2.57$ (Table 5). The items with the highest score were item $1(1.76 \pm 0.43)$ and item $2(1.57 \pm 0.73)$. These items showed the need for assistance during meals and averaged $1.66 \pm 0.58$. Items 3 and 4 , indicators of the person's difficulty in eating alone, averaged $0.54 \pm 0.53$. Items $5-10$, which describe the behaviors that reflect signs of functional or cognitive decline, had an average value of $0.17 \pm 0.41$.

There were no statistically significant correlations or differences between the final EdFED-PT score and PwD age $\left(r_{\mathrm{s}}=-0.01, p=0.946\right)$, sex $(\mathrm{U}=109.5, p=0.219)$, or institutionalization time $\left(r_{\mathrm{s}}=0.221, p=0.119\right)$.

\section{Discussion and Conclusion}

This study aimed to contribute to the adaptation of the EdFED to the Portuguese population. It was intended to analyze its internal consistency and interobserver reliability, in addition to characterizing the feeding difficulties of institutionalized $\mathrm{PwD}$, including an analysis of the relationship between the participants' sociodemographic variables and the results of the EdFED.

From the cultural and linguistic translation and validation phase, the appropriate version for the Portuguese population emerged, with a CVI of 0.950 . This value is in accordance with that recommended in the literature, 
Table 3. Internal consistency of the EdFED-PT $(n=51)$

\begin{tabular}{|c|c|c|c|}
\hline Item & $\begin{array}{l}\text { Score, } \\
\text { mean } \pm S D\end{array}$ & $\begin{array}{l}\text { Item-total } \\
\text { correlation }\end{array}$ & $\begin{array}{l}\text { Cronbach's a } \\
\text { if item deleted }\end{array}$ \\
\hline 1. Does the patient require close supervision while feeding? & $1.76 \pm 0.428$ & 0.463 & 0.668 \\
\hline 3. Is there spillage while feeding? & $0.90 \pm 0.640$ & 0.236 & 0.714 \\
\hline 4. Does the patient tend to leave food on the plate at the end of the meal? & $0.18 \pm 0.434$ & 0.650 & 0.726 \\
\hline 5. Does the patient ever refuse to eat? & $0.27 \pm 0.568$ & 0.512 & 0.653 \\
\hline 8. Does the patient spit out his food? & $0.06 \pm 0.238$ & 0.229 & 0.703 \\
\hline 9. Does the patient leave his mouth open allowing food to drop out? & $0.16 \pm 0.418$ & 0.417 & 0.676 \\
\hline 10. Does the patient refuse to swallow? & $0.20 \pm 0.448$ & 0.663 & 0.634 \\
\hline
\end{tabular}

EdFED-PT, Portuguese version of the Edinburgh Feeding Evaluation in Dementia Scale; SD, standard deviation.

Table 4. EdFED-PT interobserver reliability $(n=40)$

\begin{tabular}{|c|c|c|c|c|c|c|c|c|c|}
\hline & never & sometimes & often & never & sometimes & often & $\kappa$ & $p$ value & $\mathrm{C}$ \\
\hline 2 & 7 (17.5\%) & $6(15 \%)$ & $27(67.5 \%)$ & $7(17.5 \%)$ & $6(15 \%)$ & $27(67.5 \%)$ & 1 & $<0.01$ & 100 \\
\hline 3 & $12(30 \%)$ & $21(52.5 \%)$ & $7(17.5 \%)$ & $12(30 \%)$ & $20(50 \%)$ & $8(20 \%)$ & 0.959 & $<0.01$ & 97.5 \\
\hline 4 & $32(80 \%)$ & $7(17.5 \%)$ & $1(2.5 \%)$ & $33(82.5 \%)$ & $6(15 \%)$ & $1(2.5 \%)$ & 0.920 & $<0.01$ & 97.5 \\
\hline 7 & $34(85 \%)$ & $6(15 \%)$ & - & $35(87.5 \%)$ & $5(12.5 \%)$ & - & 0.895 & $<0.01$ & 97.5 \\
\hline 8 & $37(92.5 \%)$ & $3(7.5 \%)$ & - & $38(95 \%)$ & $2(5 \%)$ & & 0.787 & $<0.01$ & 97.5 \\
\hline 9 & $36(90 \%)$ & $3(7.5 \%)$ & $1(2.5 \%)$ & $35(87.5 \%)$ & $3(7.5 \%)$ & $2(5 \%)$ & 0.757 & $<0.01$ & 95 \\
\hline 10 & $35(87.5 \%)$ & $5(12.5 \%)$ & - & $35(87.5 \%)$ & $5(12.5 \%)$ & - & 1 & $<0.01$ & 100 \\
\hline
\end{tabular}

C, percentage of agreement; EdFED-PT, Portuguese version of the Edinburgh Feeding Evaluation in Dementia Scale. * No statistical test was calculated because the variable was constant.

which suggests values $>0.8$ when the panel of experts is composed of more than six subjects $[17,21]$, and that in checking the validity of new instruments the values recommended by Polit and Beck [17] must be $>0.900$. Although other EdFED translation and adaptation studies used retroversion processes followed by expert evaluation, only the Chinese versions evaluated the content validity by calculating the CVI, obtaining values of 0.969 for traditional Chinese (Taiwan) and 1.0 for simplified Chinese (Mainland China) [7, 8].

Content validity refers to the degree to which each item is relevant and representative of a construct with a specific objective of evaluation and is fundamental in the process of developing or adapting evaluation instruments [22-25]. The CVI measures the proportion of experts who are in agreement on the items of the instrument, and when its value is $\geq 0.800$ in all items evaluated, the validation process is concluded [26].

During the cultural adaptation of the instrument, the evaluation by the panel of experts was a crucial point to guarantee the robustness of the process. Attention should be paid to the number and qualification of the experts, and some authors recommend 5-10 experts [21] and others suggest a minimum of 6 up to 20 experts [22].

According to the instrument's characteristics and theme, the academic graduation, qualification, and availability of the participants must be considered, who must have clinical and/or research experience in the theme, and when dealing with a process of cultural adaptation, formation of a multidisciplinary commission is suggested 
Table 5. Results of feeding difficulties assessed using the EdFED-PT $(n=51)$

\begin{tabular}{|c|c|}
\hline Item & $\begin{array}{l}\text { Score, } \\
\text { mean } \pm S D\end{array}$ \\
\hline 1. Does the patient require close supervision while feeding? & $1.76 \pm 0.43$ \\
\hline 2. Does the patient require physical help with feeding? & $1.57 \pm 0.73$ \\
\hline 3. Is there spillage while feeding? & $0.90 \pm 0.64$ \\
\hline 4. Does the patient tend to leave food on the plate at the end of the meal? & $0.18 \pm 0.43$ \\
\hline 5. Does the patient ever refuse to eat? & $0.27 \pm 0.57$ \\
\hline 6. Does the patient turn his head away while being fed? & $0.06 \pm 0.24$ \\
\hline 7. Does the patient refuse to open his mouth? & $0.29 \pm 0.54$ \\
\hline 8. Does the patient spit out his food? & $0.06 \pm 0.24$ \\
\hline 9. Does the patient leave his mouth open allowing food to drop out? & $0.16 \pm 0.42$ \\
\hline 10. Does the patient refuse to swallow? & $0.20 \pm 0.45$ \\
\hline Total score & $5.45 \pm 2.57$ \\
\hline
\end{tabular}

EdFED-PT, Portuguese version of the Edinburgh Feeding Evaluation in Dementia Scale; SD, standard deviation.

[26]. The group of eight experts formed for this study had professionals with a high academic level (all $\mathrm{PhD}$ ) in different areas, from social sciences to health sciences, with experience in the field of aging and/or dementia, and contributed to obtaining a global, judicious, and credible assessment. The group's specialization and multidisciplinarity were essential for the rigor in the validation process, since dementia requires varied and specific knowledge. Specifically, the presence of nurses, speech therapists, and gerontologists were an asset, given that these professionals deal directly with the issues of aging and also with feeding.

After the EdFED's external evaluation, with content evaluation using an expert panel, internal evaluation was performed through the study of its psychometric properties. These are parameters that indicate the quality and scientific value of the results obtained after the application of an evaluation instrument [27]. Due to the importance of the assessment instrument for both research and clinical practice, studying its qualities is essential to ensure that the researchers and/or professionals will have consistent tools at their disposal [27].

The EdFED-PT showed reasonable internal consistency (Cronbach's $\alpha=0.705)$ according to the criteria of Pestana and Gageiro [19]. Exclusion of any of the 10 items would not increase the a value. Other authors established different values for the classification of Cronbach's $\alpha$, such as DeVellis [28], who considers an a value between 0.70 and 0.80 to be respectable. In exploratory studies, the a value may decrease to 0.60 [29], provided that the results obtained are interpreted with caution [30].

Portuguese Adaptation of the Edinburgh

Feeding Evaluation in Dementia Scale
The internal consistency defined by calculating Cronbach's a was evaluated in studies of the original, Spanish, and Chinese versions. Therefore, despite having a lower value than those found in the original version $(\alpha=0.870)$ [31], the Spanish version $(\alpha=0.880)$ [9], the simplified Chinese version $(\alpha=0.910)$ [7], and the traditional Chinese version $(\alpha=0.900)$ [8], it is possible to consider that the EdFED-PT has satisfactory internal consistency. However, in these studies the sample size was $>100 \mathrm{PwD}$, twice the sample in this study (51 participants). It is standardized to have at least 10 participants per item of the instrument. In this study, for each item five participants were obtained, with a minimum recommended value [29]. Additionally, according to Conroy [32], samples $>30$ can already reliably measure an $\alpha$ value. Future studies should increase the sample size to measure the values of internal consistency and allow a more accurate comparison with the other validation studies.

Regarding the study of the EdFED-PT's interobserver reliability, the results were quite satisfactory. There was almost perfect agreement between the observers [20]: Cohen's $\kappa=0.882$ and $98.5 \%$ agreement. In the EdFED's previous translation studies, interobserver reliability was analyzed in the English, Spanish, and simplified Chinese versions, which obtained good results. However, the methodology was different from the one chosen for the present study. Pearson's correlation was used in the English [33] and simplified Chinese [7] versions, obtaining $r=0.59(p=0.013)$ and $r=0.81(p<0.0001)$, respectively. In the Spanish version [9] the authors evaluated interobserver reliability by calculating the intraclass correlation 
coefficient between observations made by nurses and professional caregivers $(0.94, p<0.0001)$, nurses and family caregivers $(0.81, p<0.0001)$, and between professional caregivers and family caregivers $(0.78, p<0.0001)$. Although it was stipulated by a different method, this study demonstrated that the EdFED-PT also has satisfactory interobserver reliability.

The methodology used in each EdFED translation and validation study was different, as was the sample of each one. Samples of PwD ranged from 26 in the Canadian study [10] to 262 in the Spanish translation [9]. The mean age of the PwD in the present study was $86.06 \pm 6.77$ years, slightly higher than the average age of previous studies $(80.82 \pm 10.02$ years). The probability of increasing the severity of dementia as well as the need for institutionalization and mortality vary according to age and dementia stage [34]; therefore, within about 5 years, which was the difference in the mean of age between studies, the trajectory of dementia can cause differences in symptoms with advancing age. A predominance of the female sex occurred in this and other validation studies [7-11], being slightly higher in the current research: 86.2 vs. $76.5 \%$ of women. Two-thirds of clinically diagnosed dementia cases are in women [35]. This is justified by the fact that women have greater longevity and are thus more susceptible to developing the condition.

In addition to the exploratory study of the EdFED-PT's psychometric properties, this study was valued with the application of the instrument to a group of institutionalized PwD in order to characterize their feeding difficulties.

Participants had an average EdFED-PT score of 5.45. The items with the highest score were item 1 (1.76) and item 2 (1.57), indicating that the sample has a great need for assistance at the time of the meal. There were some behaviors indicative of functional and cognitive decline, with refusal to eat and to open the mouth being the ones that occurred most frequently. The fact that the observation occurred in just one meal limits the result of the assessment to the behavior of the PwD at that time. Participants who performed well at the time of observation could be on a "good" day, when the PwD was to have more difficulty with meals. The opposite situation can also occur, when a person who usually eats with great difficulty performed well at the time of observation. An evaluator who had more knowledge of both the instrument and the person to be observed could increase the likelihood of a more reliable assessment.

Sociodemographic variables (age, sex, and length of institutionalization) were not significantly associated with feeding difficulties of older PwD in this study. A probable explanation for these results may be due to the possibility of having in the sample people with different stages of dementia, since dementia itself implies a trajectory with some unpredictability. A better characterization of the type and degree of dementia in future studies could point to some relationship between the stage of dementia and the result obtained at EdFED.

The main limitation of this study focuses on the fact that the sample was small, which compromises the generalization of the results to the Portuguese institutionalized population with dementia. Although the institutions that participated in this study had an occupancy rate of $100 \%$, a limitation in the selection of participants was underrecording of the diagnosis of dementia in the clinical process. This factor contributed to reducing the number of participants, as this was one of the main inclusion criteria. Another limitation was the absence of more data regarding the type and degree of dementia recorded in the clinical process of the participants. The history of the disease was, in most cases, not very detailed. In future studies, it is suggested that the application of assessment instruments better characterize the participants' cognitive and functional status.

Furthermore, validation analyses (e.g., construct validity) were not possible due to the small sample size. The adapted Portuguese version of the EdFED and its reliability analysis were a first step to providing a tool that allows assessing the feeding difficulties experienced by $\mathrm{PwD}$ and provides early-action solutions other than standard practice in this situation. Nevertheless, a confirmatory factor analysis of this version is needed, and further studies should test the replicability of the three-factor model, qualities, and proportions of the original EdFED.

Another limitation was the use of data analysis methodology different from that used in the translation and validation of the EdFED into other languages, thus making it difficult to compare the results.

Future studies could correlate the final score with a nutritional assessment scale to explore if, or how, the feeding difficulties presented are related to nutritional status and caloric intake. Studies evaluating other psychometric properties, such as intraobserver reliability, would also increase the knowledge about EdFED-PT psychometric properties.

\section{Conclusion}

The main objective of this study was to contribute to translation and adaptation of the EdFED to the Portuguese population, in addition to studying some of its psy- 
chometric properties and analyzing the relationship between sociodemographic variables and the results of the scale. By strictly following the content validation procedure and conducting an exploratory study of psychometric properties, the main results suggest that the EdFED$\mathrm{PT}$ allows to recognize feeding difficulties in institutionalized older PwD.

The EdFED-PT is considered a reliable instrument, and in addition to its assistance to determine the level of impairment as well as to evaluate the need of multidimensional intervention in feeding of older adults with dementia, it also allows comparison with international studies that use the EdFED as an evaluation tool.

\section{Statement of Ethics}

Ethical approval was obtained from the Ethics Committee of the Health Sciences Research Unit - UICISA: E (Ref. 598/062019). All participants had the informed consent term signed by a legal proxy.

\section{Conflict of Interest Statement}

The authors have no conflicts of interest to declare.

\section{Funding Sources}

This article was supported by National Funds through FCT Fundação para a Ciência e a Tecnologia within CINTESIS, R\&D Unit (reference UIDB/4255/2020).

\section{Author Contributions}

L. Passos, J. Tavares, D. Figueiredo: conception and design. L. Passos: data collection. L. Passos, J. Tavares: analysis and interpretation of data. L. Passos: writing of the manuscript. J. Tavares, D. Figueiredo: critical revision of the manuscript. J. Tavares: statistical expertise. D. Figueiredo: obtaining funding. J. Tavares, D. Figueiredo: study supervision.

\section{References}

1 Patterson C. World Alzheimer Report 2018: the state of the art of dementia research: new frontiers. London: Alzheimer's Disease International; 2018. Available from: https://www. alz.co.uk/research/WorldAlzheimerReport2018.pdf [cited March 24, 2019].

2 Alzheimer Europe. 2013: The prevalence of dementia in Europe. Luxembourg: Alzheimer Europe; 2017. Available from: https://www. alzheimer-europe.org/Policy-in-Practice2/ Country-comparisons/2013-The-prevalence-of-dementia-in-Europe [cited April 15, 2019].

3 OECD. Care needed: improving the lives of people with dementia. Paris: OECD; 2018. Available from: https://www.oecd-ilibrary. org/social-issues-migration-health/careneeded_9789264085107-en [cited April 15, 2019].

4 Cintra MT, Rezende NA, Torres HO. Qual a via mais adequada para a alimentação de idosos com demência avançada: oral ou enteral? Geriatr Gerontol Aging. 2013;7(4):308-17.

5 Batchelor-Murphy M, Crowgey S. Mealtime difficulties in dementia. In: Boltz M, Capezuti E, Fulmer T, Zwicker DA, editors. Evidence-based geriatric nursing protocols for best practice. 5th ed. New York: Springer; 2016.

6 Watson R. Measuring feeding difficulty in patients with dementia: replication and validation of the EdFED Scale \#1. J Adv Nurs. 1994 May;19(5):850-5.
7 Liu W, Watson R, Lou FL. The Edinburgh Feeding Evaluation in Dementia scale (EdFED): cross-cultural validation of the simplified Chinese version in mainland China. J Clin Nurs. 2014 Jan;23(1-2):45-53.

8 Lin LC, Chang CC. A Chinese translation of the EdFED-Q and assessment of equivalence. Alzheimer Dis Assoc Disord. 2003 Oct-Dec; 17(4):230-5.

9 Saucedo Figueredo MC, Morilla Herrera JC, Ramos Gil R, Arjona Gómez MN, García Dillana F, Martínez Blanco J, et al. Validation of the Spanish version of the Edinburgh feeding evaluation in dementia scale applied to institutionalized older persons with dementia: a study protocol. Nurs Open. 2016 Apr;3(4):236-42.

10 Côté C, Gagnon C, Payette H. Adaptation transculturelle en français du Edinburgh Feeding Evaluation in Dementia (EdFED) Scale: un questionnaire pour évaluer les difficultés à s'alimenter de personnes âgées présentant des troubles cognitifs en centre d'hébergement. Can J Aging. 2018 Dec;37(4): 474-81.

11 Bagnasco A, Watson R, Zanini M, Rosa F, Rocco G, Sasso L. Preliminary testing using Mokken scaling of an Italian translation of the Edinburgh Feeding Evaluation in Dementia (EdFED-I) scale. Appl Nurs Res. 2015 Nov; 28(4):391-6.

12 Stockdell R, Amella EJ. The Edinburgh Feeding Evaluation in Dementia Scale: determining how much help people with dementia need at mealtime. Am J Nurs. 2008 Aug; 108(8):46-54.
13 Aselage MB. Measuring mealtime difficulties: eating, feeding and meal behaviours in older adults with dementia. J Clin Nurs. 2010 Mar; 19(5-6):621-31.

14 Volkert D, Chourdakis M, Faxen-Irving G, Frühwald T, Landi F, Suominen $\mathrm{MH}$, et al. ESPEN guidelines on nutrition in dementia. Clin Nutr. 2015 Dec;34(6):1052-73.

15 Batchelor-Murphy M, Amella EJ. Eating and feeding issues in older adults with dementia: Part I: assessment. New York: The Hartford Institute for Geriatric Nursing; 2008. Available from: https://hign.org/consultgeri/trythis-series/eating-and-feeding-issues-olderadults-dementia-part-i-assessment [cited January 18, 2020].

16 Wild D, Grove A, Martin M, Eremenco S, McElroy S, Verjee-Lorenz A, et al.; ISPOR Task Force for Translation and Cultural Adaptation. Principles of good practice for the translation and cultural adaptation process for Patient-Reported Outcomes (PRO) Measures. Value Health. 2005 Mar-Apr;8(2):94104

17 Polit DF, Beck CT. The content validity index: are you sure you know what's being reported? Critique and recommendations. Res Nurs Health. 2006 Oct;29(5):489-97.

18 Zamanzadeh V, Rassouli M, Abbaszadeh A, Majd HA, Nikanfar A, Ghahramanian A. Details of content validity and objectifying it in instrument development. Nurs Pract Today. 2014;1(3):163-71.
Portuguese Adaptation of the Edinburgh Feeding Evaluation in Dementia Scale
Port J Public Health 2020;38:142-150 
19 Pestana MH, Gageiro JN. Análise de dados para ciências sociais: a complementaridade do SPSS. 5a ed. Lisboa: Edições Sílabo; 2008.

20 Landis JR, Koch GG. The measurement of observer agreement for categorical data. Biometrics. 1977 Mar;33(1):159-74.

21 Lynn MR. Determination and quantification of content validity. Nurs Res. 1986 Nov-Dec; 35(6):382-5.

22 Haynes SN, Richard DC, Kubany ES. Content validity in psychological assessment: a functional approach to concepts and methods. Psychol Assess. 1995;7(3):238-47.

23 Sireci S. The construct of content validity. Soc Indic Res. 1998;45(1-3):83-117.

24 Sireci S, Faulkner-Bond M. Validity evidence based on test content. Psicothema. 2014; 26(1):100-7.

25 Shrotryia VK, Dhanda U. Content validity of assessment instrument for employee engagement. SAGE Open. 2019;9(1):1-7.
26 Alexandre NM, Coluci MZ. Validade de conteúdo nos processos de construção e adaptação de instrumentos de medidas. Cien Saude Colet. 2011 Jul;16(7):3061-8.

27 Pilatti LA, Pedroso B, Gutierrez GL. Propriedades psicométricas de instrumentos de avaliação: um debate necessário. Rev Bras Ensino Ciência e Tecnol. 2010;3(1):81-91.

28 DeVellis RF. Scale development: theory and applications. 3rd ed. Los Angeles (CA): Sage Publications; 2012.

29 Hair JF, Anderson RE, Tatham RL, Black WC. Análise multivariada de dados. 6a ed. Porto Alegre. Bookman. 2009.

30 Maroco J, Garcia-Marques T. Qual a fiabilidade do alfa de Cronbach? Questões antigas e soluções modernas? Lab Psicol. 2006;4(1):6590.
31 Watson R, Deary IJ. Measuring feeding difficulty in patients with dementia: multivariate analysis of feeding problems, nursing intervention and indicators of feeding difficulty. J Adv Nurs. 1994 Aug;20(2):283-7.

32 Conroy RM. The RCSI Sample size handbook: technical report. Dublin: RCSI Royal College of Surgeons in Ireland; 2016.

33 Watson R, MacDonald J, McReady T. The Edinburgh Feeding Evaluation in Dementia Scale \#2 (EdFED \#2): inter- and intra-rater reliability. Clin Eff Nurs. 2001;5(4):184-6.

34 Davis M, O Connell T, Johnson S, Cline S, Merikle E, Martenyi F, et al. Estimating Alzheimer's Disease progression rates from normal cognition through mild cognitive impairment and stages of dementia. Curr Alzheimer Res. 2018;15(8):777-88.

35 Beam CR, Kaneshiro C, Jang JY, Reynolds CA, Pedersen NL, Gatz M. Differences between women and men in incidence rates of dementia and Alzheimer's Disease. J Alzheimers Dis. 2018;64(4):1077-83. 